Available online at www.refaad.com

VMPH 1(2); $2020: 41-47$

Research Article

Veterinary Medicine and Public Health Journal (VMPH)

Journal Homepage: https://www.refaad.com/views/vmph/home.aspx

www.refaad.com

ISSN : 2707-7195(Online) 2707-7187(Print)

\title{
Multidrug-Resistant Klebsiella pneumoniae Phylogroup KpI in Dogs and Horses at Veterinary Teaching Hospital
}

\author{
Amanda Keller Siqueira a, ${ }^{*}$, Taila dos Santos Alves b, Marília Masello Junqueira Franco c, Mirtis Maria Giaciani

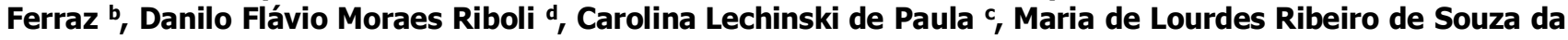 \\ Cunha d, Márcio Garcia Ribeiro c, Domingos da Silva Leite ${ }^{\text {b }}$ \\ a Dept. Medicina Veterinária, Universidade Estadual do Centro-Oeste- UNICENTRO, Guarapuava, Paraná, Brazil. \\ b Dept. Genética, Evolução, Microbiologia e Imunologia, Instituto de Biologia- Universidade Estadual de Campinas- UNICAMP, \\ Campinas, São Paulo, Brazil. \\ c Dept. Higiene Veterinária e Saúde Pública, Faculdade de Medicina Veterinária e Zootecnia, Universidade Estadual Paulista \\ -UNESP, Botucatu, São Paulo, Brazil. \\ d Dept. Microbiologia e Imunologia, Instituto de Biociências, Universidade Estadual Paulista- UNESP, Botucatu, São Paulo, \\ Brazil. \\ *Corresponding author: Amanda Keller Siqueira (kellersiqueira@hotmail.com)
}

How to cite this article: Siqueira et al. Multidrug-Resistant Klebsiella Pneumoniae Phylogroup KpI in Dogs and Horses at Veterinary Teaching Hospital. Veterinary Medicine and Public Health Journal 1(2); 2020:41-47.

DOI: https://doi.org/10.31559/vmph2020.1.2.3

Received Date: 23/2/2020 Accepted Date: 17/4/2020

\begin{abstract}
The constant isolation of antimicrobial resistant bacteria from animals poses a serious risk to public health, due to the close relationship between humans and domestic animals as dogs, cats, and horses, mainly. Antimicrobial resistance determinants can be spread among bacterial populations from community or hospital and transmitted to people in close contact with animals, such as their owners and veterinary staff. We characterize the antimicrobial resistance and the genetic relationship among five Klebsiella pneumoniae multidrug-resistant isolated from canine and one isolated from a horse in a Veterinary Teaching Hospital in Brazil. Antimicrobial resistance was investigated using disk diffusion assay and ESBL genes by PCR. Identification of the Klebsiella species and phylogroups were perform combining the PCR and RFLP techniques. Inc/replicons groups were detected by PCR based replicon typing and clonal relatedness was assessed by pulsed-field gel electrophoresis. The six isolates were identified as multidrug-resistant (MDR) K. pneumoniae belonging to phylogenetic group KpI. blactх-м, blashv, and blaтем genes were found, and blaтем was present in all ESBL-positive strains (5/6=83.3 \%), and Inc/replicons groups harbored (HI2, X, L/M, FIC, and K), associate with ESBL genes dissemination. PFGE showed genetic similarity (>95 \%) between one strain from a dog and another from the horse. This study revealed that different animal species carry multidrug-resistant bacterial clones that can be disseminated in the environment, to other animal species and humans. In this way, the widespread use or the misuse of antimicrobials may contribute to generate a population of resistant bacteria, including $K$. pneumoniae.
\end{abstract}

Keywords: pet; companion animals; beta-lactamase resistance; MDR; plasmid.

\section{Introduction}

Like in human medicine, antimicrobial resistance has emerged in veterinary hospitals and practices as a global issue (Giguère et al. 2013). Most of the antimicrobials used in veterinary therapies are also administered in human medicine, including those for exclusive use in hospitals, as some $\beta$-lactams antibiotics (Guardabassi et al. 2004).
The close contact between humans and domestic animals as dogs and cats have been established since ancient times and can even be considered a coevolution example (Amiot et al. 2016). Like dogs, horses and humans have lived together for thousands of years and these animals have been used in transportation, work, entertainment, sports, and equine-assisted therapy (Thomassian 2005). 
The emergence of $\beta$-lactam resistant bacteria in domestic animals, especially dogs and cats, and the potential dissemination of resistant strains from animals to humans poses a serious risk to public health. Antimicrobial resistance determinants can be spread among bacterial populations from community-acquired or hospital infections and transmitted to people in close contact with animals, such as their tutors and veterinary staff (Suthar et al. 2014). The risk factors involved in the transmission of resistant bacteria to humans include direct contact or the domestic environment (Guardabassi et al. 2004).

In this context, clonal spread and animal-tohuman transfer of antimicrobial genes of bacteria are concerns associated with antimicrobial resistance among commensal microorganisms. Commensal strains can act as a source of antimicrobial resistance genes to pathogens through horizontal gene transfer, although the pathways depend on several factors, e.g., the number of donors and recipients, nutrition, selective pressure and transfer mechanisms (Marshall 2009).

In developing countries, growing close populations of humans and animals provide suitable conditions for the microorganisms to adapt to human hosts (Bhatia and Narain 2010). Several factors contribute to the emergence of zoonotic pathogens: close physical contact between animals and human, easy transportation, ecological and environmental changes (Marshall 2009).

Klebsiella spp. has been more frequently isolated in outbreaks of multidrug-resistant bacterial infections in human patients, mainly as a result of the production of extended-spectrum beta-lactamases (ESBL) (Hendrik et al. 2015).

Antimicrobial resistance is a worldwide problem in health care settings due to increased morbidity rates, cost of treatment and high mortality. The overuse and the misuse of antibiotics provide selection pressure over resistant clones, contributing to the dissemination and the acquisition of resistance determinants from these lineages. Therefore, in the present study, we characterize the antimicrobial resistance pattern and the genetic relationship among five multidrug-resistant Klebsiella pneumoniae strains isolated from dogs and a horse from a Veterinary Teaching Hospital in Brazil.

\section{Material and Methods Bacterial isolates}

Six clinical multidrug-resistant $K$. pneumoniae isolates, from five dogs and one horse, were obtained from the Veterinary Microbiology Laboratory of a Veterinary Teaching Hospital located on Botucatu, São Paulo, Brazil, between July 2012 and July 2014. The isolates were first cultured from clinical samples received from veterinarians in different sectors of the Hospital.

The clinical samples were placed onto sheep blood agar (5\%) and MacConkey agar and incubated at $37{ }^{\circ} \mathrm{C}$ for 72 hours. Lactose-fermenting isolates were confirmed as $K$. pneumoniae by morphotinctorial and biochemical tests (Quinn et al. 2011). Of these, six isolates showed in vitro multidrugresistant pattern in the routine (first) antimicrobial susceptibility testing (disk diffusion method) performed in the Veterinary Microbiology Laboratory, according to the request of the veterinarians from the Teaching Hospital. Bacteria were isolated from different clinical sites, such as a wound, feces, blood, semen, and urine, respectively from the wound infection, enteritis, septicemia, orchitis, and urinary tract infection (Figure 1).

\section{Antimicrobial susceptibility testing (AST)}

The second antimicrobial susceptibility testing (AST) was performed according to CLSI recommendations (CLSI 2013, 2015, 2016), and also included the antimicrobials applied on the first test (gentamicin, florfenicol, ampicillin, ceftiofur, enrofloxacin, sulfonamide and tetracycline). Aminoglycosides (amikacin $30 \mu \mathrm{g}$; gentamicin $10 \mu \mathrm{g}$ ), amphenicols (chloramphenicol $30 \mu \mathrm{g}$, florfenicol 30 $\mu \mathrm{g}$ ), beta-lactams (amoxicillin + clavulanic acid $30 \mu \mathrm{g}$, ampicillin $10 \mu \mathrm{g}$, cephalexin $30 \mu \mathrm{g}$, cephalothin $30 \mu \mathrm{g}$, ceftiofur $30 \mu \mathrm{g}$, ceftriaxone $30 \mu \mathrm{g}$, imipenem $10 \mu \mathrm{g})$, fluoroquinolones (ciprofloxacin $5 \mu \mathrm{g}$, enrofloxacin $5 \mu \mathrm{g}$, levofloxacin 5 $\mathrm{g}$, norfloxacin $10 \mu \mathrm{g}$ ), sulfonamide (trimethoprim + sulfamethoxazole 300 UI) and tetracycline (30 $\mu \mathrm{g})$ were used in all AST tests. Multidrug resistance (MDR) was defined as resistance to three or more antimicrobial classes (Magiorakos et al. 2012). E. coli ATCC 25922 was used for quality control purposes, according to the CLSI (2013) document.

\section{Extended-spectrum $\beta$-lactamase (ESBL) phenotypic detection}

The detection of ESBL production was performed by two different methods: the double-disk synergy test (DDST) and two commercially available Etest $^{\mathrm{TM}}$ (AB Biodisk, Solna, Sweden). The DDST was done using aztreonam $(30 \mu \mathrm{g})$, ceftriaxone $(30 \mu \mathrm{g})$, cefotaxime $(30 \mu \mathrm{g})$ and ceftazidime $(30 \mu \mathrm{g})$ disks placed at $20 \mathrm{~mm}$, center to center, from amoxicillin/clavulanic acid (30 $\mu \mathrm{g})$ disks (CLSI 2016).

The Etest $\mathrm{E}^{\mathrm{TM}}$ was performed according to the manufacturer's instruction. One of the strips used (TZ/TZL) contains gradient concentrations ceftazidime $(0.5-32 \mu \mathrm{g} / \mathrm{mL})$ at one side and ceftazidime $(0.064-4 \mu \mathrm{g} / \mathrm{mL})$ plus clavulanic acid (4 $\mu \mathrm{g} / \mathrm{mL}$ ) at the other. The other strip used (PM/PML) contains gradient concentrations of cefepime $(0.25$ $16 \mu \mathrm{g} / \mathrm{mL})$ at one side and cefepime $(0.064-4 \mu \mathrm{g} / \mathrm{mL})$ plus clavulanic acid $(4 \mu \mathrm{g} / \mathrm{mL})$ at the other. A strain was considered ESBL-producing when there was a reduction in the minimum inhibitory concentration (MIC) of ceftazidime/cefepime $\geq 3 \log ^{2}$ dilutions in the presence of clavulanic acid or by the appearance of a phantom zone (Stürenburg et al. 2004).

Klebsiella pneumoniae ATCC 700603 was used as ESBL-positive control and Escherichia coli ATCC 25922 as negative control, according to the CLSI (2016) document. 


\section{Molecular analyses \\ DNA extraction}

Each isolate was inoculated onto TSA (tryptic soy agar) at $37^{\circ} \mathrm{C}$, overnight, for confluent growth. Bacteria were suspended in $100 \mu \mathrm{L}$ sterile water and boiled at $100{ }^{\circ} \mathrm{C}$, for $10 \mathrm{~min}$. Right after, they were centrifuged at 10,000 g for $3 \mathrm{~min}$. The supernatant was collected into a new microtube and refrigerated at $-20^{\circ} \mathrm{C}$.

\section{Extended-spectrum $\beta$-lactamase (ESBL) genotypic} detection

$K$ pneumoniae producing-ESBL were additionally screened for the presence of the blacтx-м, blaтем and blashv family genes by polymerase chain reaction (PCR) as previously described (Cao et al. 2002; Boyd et al. 2004).

\section{Plasmid Replicon Typing}

The Inc/replicon groups from multidrugresistant $K$. pneumoniae strains were detected using PCR based replicon typing - PBRT (Carattoli et al. 2005).

Molecular confirmation of the genus Klebsiella and differentiation of $K$. pneumoniae and $K$ oxytoca

To confirm the genus Klebsiella and to differentiate the isolates among $K$. pneumoniae and $K$. oxytoca species, multiplex-PCR was applied, according to previously described (Chander et al. 2011).

\section{Phylogeny of Klebsiella pneumoniae}

The phylogenetic classification of $K$. pneumoniae was performed based on Brisse and Verhoef (2001) and Brisse et al. (2004) protocols, combining the PCR and RFLP techniques, aiming the identification of the isolates into the KpI, KpII and KpIII groups.

\section{Pulsed-field Gel Electrophoresis (PFGE)}

The genetic relatedness of $K$. pneumoniae was analyzed by pulsed-field gel electrophoresis (PFGE) using the XbaI restriction enzyme, according to Ribot et al. (2006). BioNumerics software (version 7.1; Applied Maths, Belgium) was used for similarity analysis, calculation of the Dice correlation coefficient, and generation of a dendrogram by the UPGMA method. Band position tolerance and optimization were adjusted to 1 and $1.2 \%$, respectively. A similarity coefficient of $80 \%$ was chosen for cluster definition.

\section{Ethical approval}

The study was approved by the Ethics Committee on Animal Use (CEUA) of the School of Veterinary Medicine and Animal Sciences, São Paulo State University, UNESP, Botucatu, SP, Brazil (protocol number 0197/2018).

\section{Results}

The six investigated isolates were obtained from five dogs with urinary tract infection (UTI), enteritis, septicemia, and surgical wound infection, and from a horse with orchitis. The dogs, two females and three males ranged in age from six months to nine years, while the male horse was 18 years old. Klebsiella pneumoniae lineages were isolated from a urine sample, two rectal swabs, a catheter tip and surgical wound secretion from dogs, and the semen of the horse.

The AST revealed the following resistance profiles: aminoglycosides (amikacin, $100 \%$ resistant; gentamicin, $\quad 100 \%$ resistant); amphenicols (chloramphenicol, $100 \%$ resistant; florfenicol, $100 \%$ resistant); beta-lactams (amoxicillin + clavulanic acid, $66.7 \%$ resistant; ampicillin, $100 \%$ resistant; cephalexin, $100 \%$ resistant; cephalothin, $100 \%$ resistant; ceftiofur, $100 \%$ resistant; ceftriaxone, 100 $\%$ resistant; imipenem, $16.7 \%$ resistant); fluorquinolones (ciprofloxacin, $66.7 \%$ resistant; enrofloxacin, $100 \%$ resistant; levofloxacin, $83.3 \%$ resistant; norfloxacin, $100 \%$ resistant); sulfonamide (trimethoprim + sulfamethoxazole, $83.3 \%$ resistant) and tetracycline, $50 \%$ resistant. AST results showed that all isolates were resistant to at least one drug from three or more antimicrobials classes, thus, multidrug-resistant (MDR) (Figure 1).

Five (83.3 \%) Klebsiella pneumoniae (four isolates from dogs and the isolate from the horse) were ESBL producers. Also, strains harbored ESBLfamily genes: blacтх-м in one $(16.7 \%)$ isolate from a $\mathrm{dog}$, blaтем in five ( $83.3 \%$ ) isolates (four isolates from dogs and the one from the horse), and blashv in three $(50 \%)$ isolates from dogs (Figure 1$)$.

The Klebsiella pneumoniae strains harbored the Inc/replicon groups HI2, X, L/M, FIC, and K. FIC was identified in five isolates and $\mathrm{L} / \mathrm{M}$ in four. One strain did not display any of the replicons tested (Figure 1).

All isolates were identified as Klebsiella pneumoniae by biochemical and molecular assays. The six isolates were placed into phylogenetic group KpI.

The PFGE generated more than eight chromosomal DNA fragments for each Klebsiella pneumoniae isolate. Six XbaI-macrorestriction patterns (a-f) were obtained, and two pulsotypes (one from a dog and another from the equine) were closely related ( $95.2 \%$ of similarity) (Figure 1).

\section{Discussion}

The present study report six MDR Klebsiella pneumoniae isolates, mainly ESBL-producing (blactxм, blasнv, and blaтем), obtained from domestic animal infections presented at a Veterinary Teaching Hospital in Brazil. All of them highlights a public health issue due to the emergence of bacterial resistance worldwide, particularly to extendedspectrum cephalosporins among livestock and companion animals.

Klebsiella spp. is considered an opportunistic pathogen often isolated from animal and human infections. In humans, this microorganism causes infections predominantly in hospitalized and immunocompromised patients. The diagnosis based only in phenotypic properties may be erroneous, since $K$. pneumoniae, $K$. oxytoca, and $K$. aerogenes (formerly Enterobacter aerogenes), can generate 


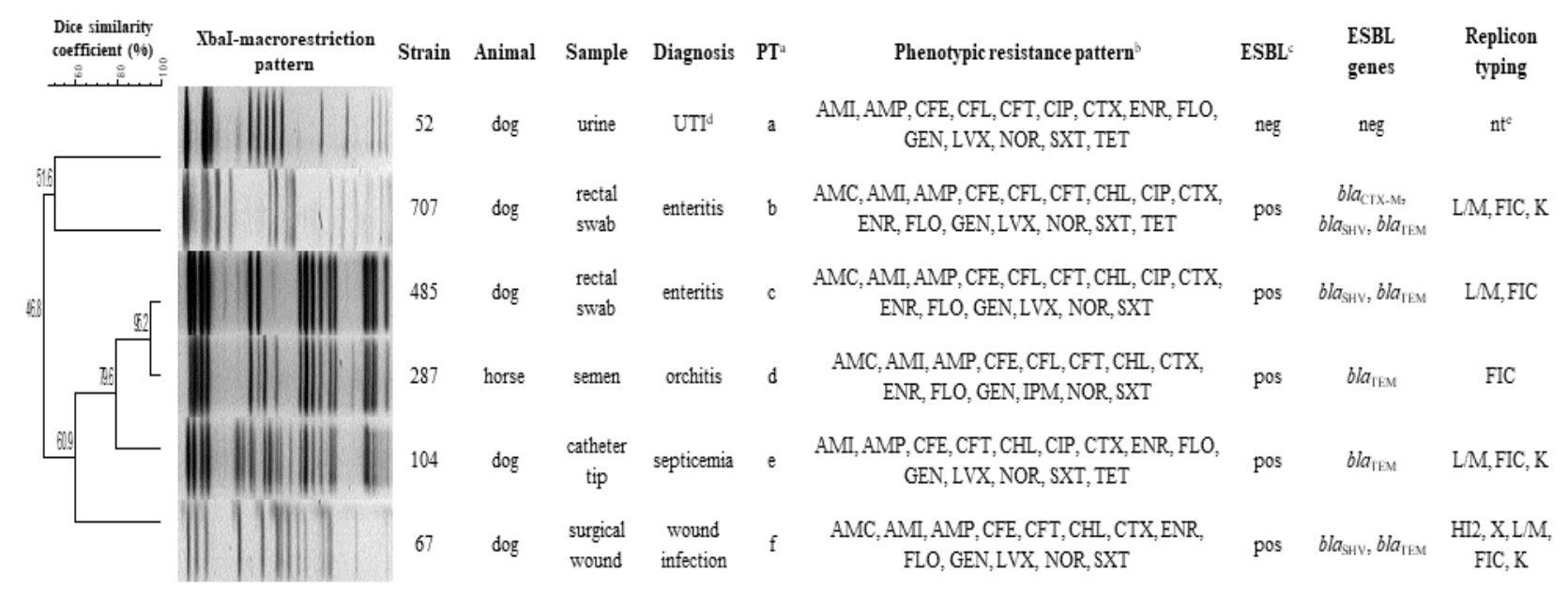

Figure (1): Dendrogram of the XbaI-macrorestriction patterns of six multidrug-resistance Klebsiella pneumoniae KpI-type isolated from dogs and equine, and their characteristics.

aPT, Pulsotype.

bAMC, amoxicillin + clavulanic acid; AMI, amikacin; AMP, ampicillin; CFE, cephalexin; CFL, cephalothin; CFT, ceftiofur; CHL, chloramphenicol; CIP, ciprofloxacin; CTX, ceftriaxone; ENR, enrofloxacin; FLO, florfenicol; GEN, gentamicin; IPM, imipenem; LVX, levofloxacin; NOR, norfloxacin; SXT, trimethoprim + sulfamethoxazole; TET, tetracycline.

cESBL tests, Klebsiella pneumoniae were positive (pos)/negative (neg) on the double disk synergy test and/or ESBL strips. dUTI, urinary tract infection.

ent, not-typeable by PCR-based replicon typing.

very similar biochemical profiles (Chander et al. 2011).

This microorganism is able to colonize mucous membranes, compromising mainly the urinary and respiratory tracts, evolving into severe pneumonia and bacteremia, with high morbidity and mortality rates (Martinez and Trabulsi 2008). In animals, the most common infections occur in the urinary and respiratory tract, pyometra and septicemia. There are also reports of Klebsiella isolation from mastitis in dairy cows, metritis in mares, and other types of infection in dogs and birds (Brisse and van Duijikeren 2005; Harada et al. 2016).

In addition, the genetic analysis of populations and the analysis of phylogenetic relationship among strains have shown great utility in determining the epidemiological patterns of bacterial dissemination and the evolution of its pathogenicity (Brisse and Verhoef 2001). The molecular analysis of the $K$. pneumoniae, using multiplex-PCR, confirmed the genus Klebsiella and identified the six isolates as $K$. pneumoniae in all samples, showing concordance between biochemical and molecular analysis.

Historically, the taxonomic position of the genus Klebsiella has undergone several reclassifications. $K$. pneumoniae can be classified into the three phylogenetic groups KpI, KpII and KpIII. KpI is associated with plants and animals, represents more than $80 \%$ of $K$. pneumoniae isolates and resistance and virulence indexes are higher when compared to $\mathrm{KpII}$ and KpIII. KpIII is mainly associated with plants and is represented by Klebsiella variicola. All three phylogroups have been described as causing agents of human infections (Brisse and van Duijkeren 2005; Holt et al. 2015).

Holt et al. (2015) proposed that phylogeny is assigned to specific species: $\mathrm{KpI}$ as $K$. pneumoniae, KpII for K. quasipneumoniae and KpIII as K. variicola, and they are collectively referred as $K$. pneumoniae complex. Following the findings of Brisse et al. (2004) who observed the KpI classification in more than $82 \%$ of clinical isolates of animals, we were able to classify our six isolates into the KpI phylogroup, all of them classified as multidrug-resistant, showing resistance to at least five antimicrobial classes.

Among the Enterobacteriaceae, K. pneumoniae is the species that presents the greatest diversity of resistance phenotypes associated with ESBL production, and where beta-lactamases are more commonly found (Bonnet 2004), specially CTX-M, SHV and TEM types (Bradford 2001). In our study, we found K. pneumoniae harboring ESBL genes (blacтх-м, blasнv, and blaтем) isolated from dogs and one horse, indicating the emergence of extended-spectrum cephalosporin resistance in strains from animals treated in a Veterinary Hospital. This fact could pose a risk to other patients and the veterinary staff.

Multidrug-resistant $K$. pneumoniae have been described in both healthy or diseased dogs and horses, from diverse sites of infection, worldwide (Harada et al. 2016; Sharif et al. 2017; Marques et al. 2018; Hong et al. 2019; Roza et al. 2019) as well as in Brazil (Carneiro et al. 2017; Melo et al. 2018). K. pneumoniae third-generation cephalosporinresistant were included in the Priority 1 group, the most critical one, of the WHO (2017) antibioticresistant "priority pathogens" list.

Recently, Bassetti et al. (2018) discussed that MDR K. pneumoniae outbreaks in human healthcare institutions are triggered through clonal dissemination mainly due to cross-transmission. Besides, the MDR $K$. pneumoniae reservoir could be asymptomatic individuals with rectal colonization. The authors also suggested that periodic investigations for prevention and outbreaks control would be crucial. Similarly, circulating MDR $K$. 
pneumoniae strains within Veterinary Hospitals can be spread to domestic animals and humans.

In our study, genetic similarity analysis was performed aiming to found circulating clone/clones at the Veterinary Hospital, and to understand the relation between the six isolates of $K$. pneumoniae. We found two isolates of different animal species with more than $95 \%$ similarity, close resistance patterns and blaтем-positive. Our results suggest clonally spread among different animal species in that hospital (a dog and a horse). Likewise, the dendrogram generated by the six isolates, displayed similarity $\geq 46 \%$ and high agreement among the resistance patterns, highlighting the potential dissemination of bacterial resistance in sites with high selection pressure due to antimicrobials use.

We did not detect Inc/Replicons groups in the MDR strain ESBL-negative. This result indicates that the $K$. pneumoniae isolates harbor ESBL genetic determinants associated with Inc/Replicons HI2, X, $\mathrm{L} / \mathrm{M}, \mathrm{F}$, and $\mathrm{K}$, which can play a role in beta-lactam mobility (Villa et al. 2010; Carattoli et al. 2015; Dobiasova and Dolejska 2016; Rozwandowicz et al. 2017; Wyrsch et al. 2019). Interestingly, five ESBLpositive $K$. pneumoniae carried plasmids belonging to the IncF group and four of these isolates carried IncL/M plasmids, the major plasmid families occurring in Enterobacteriaceae (Carattoli et al. 2005).

The issue of antimicrobial resistance (AMR) has emerged under the "One Health" approach (the integration of human, animal and environmental health) (Hong et al. 2019). Therefore, infections caused by MDR $K$. pneumoniae represents a serious public health concern and a major therapeutic challenge, both in veterinary and human medicine. Thereby, the research of MDR bacteria in veterinary medicine needs to be continuously carried out. However, more studies are needed to investigate the potential clonal relationship among isolates from animals and Veterinary Hospitals' staff, as well as the animal and its tutors, for an epidemiological approach of the results.

\section{Conclusion}

The widespread use or the misuse of broadspectrum antimicrobials, particularly cephalosporins, may generate a population of resistant bacteria, including $K$. pneumoniae. This fact can contribute to the perpetuation of multidrugresistant strains in the environment and their dissemination to other animals and human hosts. Prevention and control methods should be adopted at veterinary hospitals to reduce indirect or crosstransmission of drug-resistant bacteria.

Acknowledgment: The authors would like to thank Fernando José Paganini Listoni for the excellent technical assistance. T.S. Alves, D.F.M. Riboli and C.L. de Paula were supported by Coordination for the Improvement of Higher Education Personnel (CAPES) and M.M.J. Franco by São Paulo Research
Foundation- FAPESP (research grant $n^{\circ}$ 2014/04929-7). The funders had no role in study design, data collection and analysis, decision to publish, or preparation of the manuscript.

Conflict of interest: None to declare.

\section{References}

[1] Amiot. C., Bastian. B. \& Martens. P. People and companion animals: it takes two to tango. BioScience, 66(2016), 552-560, https://doi.org/10.1093/biosci/biw051

[2] Bassetti. M., Righi. E., Carnelutti. A., Graziano. E. \& Russo. A. Multidrug-resistant Klebsiella pneumoniae: Challenges for treatment, prevention and infection control. Expert Rev Anti Infect Ther. 16(2018), 749-761, https://doi.org/10.1080/14787210.2018.1522249

[3] Bhatia. R. \& Narain. P. The challenge of emerging zoonoses in Asia Pacific. Asia-Pacific J Public Health, 22(2010), 388-394, https://doi.org/10.1177/1010539510370908

[4] Bonnet. R. Growing group of extended-spectrum beta-lactamases: the CTX-M enzymes, Antimicrob Agents Chemother, 48(2004), 1-14, https://doi.org/10.1128/AAC.48.1.1-14.2004

[5] Boyd. D.A., Tyler. S., Christianson. S., McGeer. A., Muller. A.P., Willey. B.M., Bryce. E., Gardam. M., Nordmann. P., Mulvey. M.R. \& The Canadian Nosocomial Infection Surveillance Program, Health Canada. Complete nucleotide sequence of a 92-kilobase plasmid harboring the CTX-M-15 extended-spectrum Beta-Lactamase involved in an outbreak in long-term-care facilities in Toronto, Canada, Antimicrob Agents Chemother, 48(2004), 3758-3764 https://doi.org/10.1128/AAC.48.10.3758-3764.2004

[6] Bradford. P.A. Extended-spectrum betalactamases in the 21st century: characterization, epidemiology, and detection of this important resistance threat. Clin Microbiol Rev, 14(2001), 933-951, https://doi.org/10.1128\%2FCMR.14.4.933951.2001

[7] Brisse. S. \& Verhoef. J. Phylogenetic diversity of Klebsiella pneumoniae and Klebsiella oxytoca clinical isolates revealed by randomly amplified polymorphic DNA, gyrA and parC genes sequencing and automated ribotyping. Int J Syst Evol Microbiol, 51(2001), 915-924, https://doi.org/10.1099/00207713-51-3-915

[8] Brisse. S., van Himbergen. T., Kusters. K. \& Verhoef. J. Development of a rapid identification method for Klebsiella pneumoniae phylogenetic groups and analysis of 420 clinical isolates. Clin Microbiol Infect., 10(2004), 942-945, https://doi.org/10.1111/j.1469-0691.2004.00973.x

[9] Brisse. S. \& van Duijkeren. E. Identification and antimicrobial susceptibility of 100 Klebsiella animal clinical isolates. Vet Microbiol., 105(2005), 307-312, https://doi.org/10.1016/j.vetmic.2004.11.010

[10] Cao. V., Lambert. T., Nhu. D.Q., Loan. H.K., Hoang. N.K., Arlet. G. \& Courvalin. P. Distribution of extended-spectrum $\beta$-lactamases in clinical 
isolates of Enterobacteriaceae in Vietnam. Antimicrob Agents Chemother., 46(2002), 3739-3743. https://doi.org/10.1128/aac.46.12.37393743.2002

[11] Carattoli. A. Bertini. A., Villa. L., Falbo. V., Hopkins. K.L., \& Threlfall. E.J. Identification of plasmids by PCR-based replicon typing. J Microbiol Methods, 63(2005), 219-228. https://doi.org/10.1016/j.mimet.2005.03.018

[12] Carattoli. A., Seiffert. S.N., Schwendener. S., Perreten. V. \& Endimiani. A. Differentiation of IncL and IncM plasmids associated with the spread of clinically relevant antimicrobial resistance. PLoS One, 10(2015), 1-14, https://doi.org/10.1371/journal.pone. 0123063

[13] Carneiro. V.C., Lessa. D.A.B., Guttmann. P.M., Magalhães. H., Aquino. M.H.C., Cunha. L.E.R., Arais. L.R. \& Cerqueira. A.M.F. Virulence, resistance, and genetic relatedness of Escherichia coli and Klebsiella sp. isolated from mule foals. Arq Bras Med Vet Zootec., 69(2017), 1073-1082, http://doi.org/10.1590/1678-4162-9115

[14] Chander. Y., Ramakrishnam. M.A., Jindal. N., Hanson. K. \& Goyal. S.M. Differentiation of Klebsiella pneumoniae and $K$. oxytoca by multiplex polymerase chain reaction. Int J App Res Vet Med., 9(2011), 138-142.

[15] Clinical and Laboratory Standards Institute (CLSI), Performance standards for antimicrobial disk and dilution susceptibility tests for bacteria isolated from animals; Approved standard Fourth edition. CLSI document VET01-A4, Clinical and Laboratory Standards Institute; Wayne, PA, USA, (2013).

[16] Clinical and Laboratory Standards Institute (CLSI), Performance standards for antimicrobial disk and dilution susceptibility tests for bacteria isolated from animals; 3rd ed. CLSI supplement VET01S, Clinical and Laboratory Standards Institute, Wayne, PA, USA, (2015).

[17] Clinical and Laboratory Standards Institute (CLSI), Performance standards for antimicrobial susceptibility testing; 26th ed. CLSI supplement M100S, Clinical and Laboratory Standards Institute; Wayne, PA, USA, (2016).

[18] Dobiasova. H. \& Dolejska. M. Prevalence and diversity of IncX plasmids carrying fluoroquinolone and $\beta$-lactam resistance genes in Escherichia coli originating from diverse sources and geographical areas. J Antimicrob Chemother., 71(2016), 2118-2124, https://doi.org/10.1093/jac/dkw144

[19] Giguère. S., Prescott. J.F. \& Dowling. P.M. Antimicrobial therapy in Veterinary Medicine, ed. Wiley-Blackwell, Iowa, (2013).

[20] Guardabassi. L., Schwarz. S. \& Lloyd. D.H. Pet animals as reservoirs of antimicrobial resistant bacteria. J Antimicrob Chemother., 54(2004), 321-332, https://doi.org/10.1093/jac/dkh332

[21] Harada. K., Shimizu. T., Mukai. Y., Kuwajima. K., Sato. T., Usui. M., Tamura., Y., Kimura. Y., Miyamoto. T., Tsuyuki. Y., Ohki. A. \& Kataoka. Y. Phenotypic and molecular characterization of antimicrobial resistance in Klebsiella spp. isolates from companion animals in Japan: Clonal dissemination of multidrug-resistant Extended-Spectrum $\beta$-lactamase-producing Klebsiella pneumoniae, Front Microbiol. 7(2016),

$1-12$, https://doi.org/10.3389/fmicb.2016.01021

[22] Hendrik. T.C., Voor. A.F. \& Vos. M.C. Clinical and molecular epidemiology of extended-spectrum beta-lactamase-producing Klebsiella spp.: a systematic review and meta-analyses. PLoS ONE, 10(2015), 1-23, https://doi.org/10.1371/journal.pone.0140754

[23] Holt. K.E., Wertheim. H., Zadoks. R.N., Baker. S., Whitehouse. C.A., Dance. D., Jenney. A., Connor. T.R., Hsu. L.Y., Severin. J., Brisse. S., Cao. H., Wilksch. J., Gorrie. C., Schultz. M.B., Edwards. D.J., Nguyen. K.V., Nguyen. T.V., Dao. T.T., Mensink. M., Minh. V.L., Nhu. N.T., Schultsz. C., Kuntaman. K., Newton. P.N., Moore. C.E., Strugnell. R.A. \& Thomson. N.R. Genomic analysis of diversity, population structure, virulence, and antimicrobial resistance in Klebsiella pneumoniae, an urgent threat to public health. Proc Natl Acad Sci., 112(2015), 1-8, https://doi.org/10.1073/pnas.1501049112

[24] Hong. J.S., Song. W., Park. H-M., Oh. J-Y., Chae. JC., Shin. S. \& Jeong. S.H. Clonal spread of extended-spectrum cephalosporin-resistant enterobacteriaceae between companion animals and humans in South Korea, Front Microbiol., 18(2019), 1-8, https://doi.org/10.3389/fmicb.2019.01371

[25] Magiorakos. A.P., Srinivasan. A., Carey. R.B., Carmeli. Y., Falagas. M.E., Giske. C.G., Harbarth. S., Hindler. J.F., Kahlmeter. G., Olsson-Liljequist. B., Paterson. D.L., Rice. L.B., Stelling. J., Struelens. M.J., Vatapoulos. A., Weber. J.T. \& Monnet. D.L. Multidrug-resistant, extensively drug-resistant and pandrug-resistant bacteria: an international expert proposal for interim standard definitions for acquired resistance. Clin Microbiol Infect., 18(2012), 268-281, https://doi.org/10.1111/j.14690691.2011.03570.x

[26] Marques. C., Menezes. J., Belas. A., Aboim. C., Cavaco-Silva. P., Trigueiro. G., Gama. L.T. \& Pomba. C. Klebsiella pneumoniae causing urinary tract infections in companion animals and humans: population structure, antimicrobial resistance and virulence genes. J Antimicrob Chemother., 74(2019), 594-602, https://doi.org/10.1093/jac/dky499

[27] Martinez. M.B. \& Trabulsi. L.R. Enterobacteriaceae, in: Trabulsi, L.R. \& Alterthum, F. (Eds.), Microbiologia, ed. Atheneu, São Paulo, pp. 271-280, (2008).

[28] Marshall. B.M., Ochieng. D.J. \& Levy. S.B. Commensals: Underappreciated Reservoir of antibiotic resistance, Microbe, 4(2009), 231235.

[29] Melo. L.C., Oresco. C., Leigue. L., Netto. H.M., Melville. P.A., Benites. N.R., Saras. E., Haenni. M., Lincopan. N. \& Madec. J.Y. Prevalence and molecular features of ESBL/pAmpC-producing 
Enterobacteriaceae in healthy and diseased companion animals in Brazil. Vet Microbiol., 221(2018), 59-66, https://doi.org/10.1016/j.vetmic.2018.05.017

[30] Quinn. P.J., Markey. B.K., Leonard. F.C., Fitzpatrick. E.S., Fanning. S. \& Hartigan. P.J. Veterinary Microbiology and Microbial Disease. ed. Wiley-Blackwell, Iowa, (2011).

[31] Ribot. E.M., Fair. M.A., Gautom. R., Cameron. D.N., Hunter. S.B., Swaminathan. B. \& Barrett. T.J. Standardization of pulsed-field gel electrophoresis protocols for the subtyping of Escherichia coli 0157:H7. Salmonella, and Shigella for PulseNet, Foodborne Pathog Dis., 3(2006), 59-67, https://doi.org/10.1089/fpd.2006.3.59

[32] Roza. F.T., Couto. N., Carneiro. C., Cunha. E., Rosa. T., Magalhães. M., Tavares. L., Novais. A., Peixe. L., Rossen. J.W., Lamas. L.P. \& Oliveira. M. Commonality of multidrugresistant Klebsiella pneumoniae ST348 isolates in horses and humans in Portugal, Front Microbiol., $\quad 10(2019), \quad 1-9$, https://doi.org/10.3389/fmicb.2019.01657

[33] Rozwandowicz. M., Brouwer. M.S., Zomer. A.L., Bossers. A., Harders. F., Mevius. D.J., Wagenaar. J.A. \& Hordijk. J. Plasmids of distinct IncK lineages show compatible phenotypes. Antimicrob Agents Chemother., 61(2017), 1-5, https://doi.org/10.1128/AAC.01954-16

[34] Sharif. N.M., Sreedevi. B., Chaitanya. R.K. \& Sreenivasulu. D. Beta-lactamase antimicrobial resistance in Klebsiella and Enterobacter species isolated from healthy and diarrheic dogs in Andhra Pradesh, India, Vet World, 10(2017), 950-954,

https://dx.doi.org/10.14202\%2Fvetworld.2017.950-954

[35] Stürenburg. E., Sobottka. I, Noor. D., Laufs. R. \& Mack. D. Evaluation of a new cefepimeclavulanate ESBL Etest to detect extendedspectrum $\beta$-lactamases in an Enterobacteriaceae strain collection. J Antimicrob Chemother., 54(2004), 134-138, https://doi.org/10.1093/jac/dkw274

[36] Suthar. N., Roy. S., Call. D.R., Besser. T.E. \& Davis. M.A. An individual-based model of transmission of resistant bacteria in a Veterinary Teaching Hospital. PloS One, 9(2014), 1-11, https://doi.org/10.1371/journal.pone.0098589

[37] Thomassian. A. Afecções do aparelho locomotor (ossos e articulaçôes), in: Thomassian A. (Ed.) Enfermidades dos Cavalos, ed. Varela, São Paulo, pp. 97-136, (2005).

[38] Villa. L., García-Fernández. A., Fortini. D. \& Carattoli. A. Replicon sequence typing of IncF plasmids carrying virulence and resistance determinants. J Antimicrob Chemother., 65(2010),

2518-2529, https://doi.org/10.1093/jac/dkq347

[39] World Health Organization (WHO), Global Priority List of Antibiotic-Resistant Bacteria to Guide Research, Discovery, and Development of New Antibiotics, (2017).
[40] Wyrsch. E.R., Reid. C.J., DeMaere. M.Z., Liu. M.Y., Chapman. T.A., Chowdhury, P.R. \& Djordjevic, S.P. Complete sequences of multiple-drug resistant IncHI2 ST3 plasmids in Escherichia coli of porcine origin in Australia. Front Microbiol., 3(2019), 1-10, https://doi.org/10.3389/fsufs.2019.00018 